\title{
Bullying: prevalência, implicações e diferenças entre os gêneros
}

\author{
Cláudia de Moraes Bandeira \\ Claudio Simon Hutz
}

\begin{abstract}
Resumo
O presente estudo teve por objetivo levantar a ocorrência de bullying em crianças e adolescentes escolares da cidade de Porto Alegre. Investigou os tipos mais utilizados de bullying e a frequência com que ocorrem por sexo. Participaram 465 estudantes, sendo $52,7 \%$ do sexo masculino. O instrumento utilizado foi um questionário sobre bullying. Os resultados apontaram para um número elevado de estudantes envolvidos em bullying, bem como diferenças entre meninos e meninas quanto ao fenômeno. Concluiu-se que o bullying é um fenômeno de ocorrência muito comum no cenário escolar, o que alerta para a gravidade de um fenômeno que apresenta tantos prejuízos aos envolvidos em diferentes escolas ao redor do mundo. Novos estudos são sugeridos para esclarecer algumas das questões.
\end{abstract}

Palavras-chave: Bullying, gênero, crianças em idade escolar.

\section{Bullying: Prevalence, implications and gender differences}

\begin{abstract}
In this work we investigate the occurrence of bullying in school children and adolescents of Porto Alegre. We studied the most used types of bullying and how often they occur in sex. 465 students participated, from them $52.7 \%$ were male. The instrument used was a questionnaire on bullying. The results showed a high number of students involved in bullying, as well as differences between boys and girls involved We conclude that bullying is a very frequent phenomenon in the school setting. This becomes a warning to the seriousness of a phenomenon that brings so much harm to those involved in it, from different schools around the world. Further studies are suggested to clarify some issues.
\end{abstract}

Keywords: Bullying, gender, school age children.

\section{Bullying: Prevalencia, consecuencias y diferencias entre géneros}

El presente estudio tuvo por objetivo levantar la existencia de bullying entre niños y adolescentes escolares de la ciudad de Porto Alegre. Se investigaron los tipos más utilizados de bullying y la frecuencia con que ocurren por sexo. Participaron 465 estudiantes, siendo $52,7 \%$ de sexo masculino. El instrumento utilizado fue un cuestionario sobre bullying. Los resultados indicaron un número elevado de estudiantes involucrados en bullying, así como diferencias entre niños y niñas en relación al fenómeno. Se concluye que el bullying es un fenómeno de incidencia muy común en el escenario escolar, lo que alerta para la gravedad de un fenómeno que presenta tantos perjuicios a los involucrados en diferentes escuelas alrededor del mundo. Nuevos estudios son sugeridos para esclarecer algunas de las cuestiones levantadas.

Palabras clave: Bullying; diferencias de género, niños em edad escolar. 


\section{Introdução}

\section{Bullying: conceito, classificação e frequência}

Bullying é uma subcategoria do comportamento agressivo que ocorre entre os pares (Olweus, 1993). Constitui-se num relacionamento interpessoal caracterizado por um desequilíbrio de forças, o que pode ocorrer de várias maneiras: o alvo da agressão pode ser fisicamente mais fraco, ou pode perceber-se como sendo física ou mentalmente mais fraco que o perpetrador. Pode ainda existir uma diferença numérica, em que vários estudantes agem contra uma única vítima (Olweus, 1993; Rigby, 1998). No bullying existe a intenção de prejudicar, humilhar, e tal comportamento persiste por certo tempo, sendo mantido pelo poder exercido sobre a vítima, seja pela diferença de idade, força, ou gênero (Olweus, 1993). Existem três elementos cruciais que caracterizam o bullying, aceitos por cientistas ao redor do mundo, que são a repetição, o prejuízo e a desigualdade de poder (Berger, 2007).

O bullying tem sido classificado em diferentes tipos que incluem o físico, verbal, relacional e eletrônico (Berger, 2007). O tipo físico envolve socos, chutes, pontapés, empurrões, bem como roubo de lanche ou material. A tendência é que este tipo de ataque diminua com a idade. O tipo verbal inclui práticas que consistem em insultar e atribuir apelidos vergonhosos ou humilhantes (Berger, 2007; Rolim, 2008). Este tipo é mais comum do que o tipo físico, principalmente com o avanço da idade. O tipo relacional é aquele que afeta o relacionamento social da vítima com seus colegas. Ocorre quando um adolescente ignora a tentativa de aproximação de um colega deliberadamente. Este tipo se torna mais prevalente e prejudicial a partir da puberdade, uma vez que as crianças aprimoram mais suas habilidades sociais e a aprovação dos pares se torna essencial (Berger, 2007). O tipo eletrônico, ou cyberbullying, ocorre quando os ataques são feitos por vias eletrônicas. Este tipo inclui bullying através de e-mail, mensagens instantâneas, salas de bate-papo, web site ou através de mensagens digitais ou imagens enviadas pelo celular (Berger, 2007).

Em relação à frequência e tipos de bullying, Berger (2007) afirma que existem grandes variações entre as nações, entre as regiões de uma mesma nação e entre as escolas de uma mesma região. Para esta autora, a cultura pode ser um fator que sustenta tais variações. Outra possibilidade é que as crianças se comportam similarmente ao redor do mundo, mas a linguagem encobre o que há de comum entre elas, uma vez que o significado e conotações da palavra bullying varia amplamente através do mundo. Outra complicação é a falta de uma definição operacional comum dos três elementos que caracterizam o bullying, que são a repetição, o prejuízo e a desigualdade de poder. A referida autora aponta para um estudo realizado pela United Nation (UN) no qual o termo bullying foi definido antes da aplicação das questões do estudo. A definição foi cuidadosamente produzida e traduzida para a linguagem local, com a escolha de palavras que pudessem auxiliar as crianças a interpretar bullying da mesma forma, independente do seu conhecimento linguístico. Após lerem o conceito, 50.000 estudantes da Europa responderam a duas questões sobre bullying. Este estudo apresentou alta prevalência e grande variação. Cerca de um terço de todas as crianças que participaram deste estudo se identificaram como sendo agressores, vítimas ou ambos. As mesmas questões foram realizadas nos Estados Unidos, com um total de $30 \%$ dos estudantes de 13 anos que se identificaram como agressores ou vítimas, e no Canadá o número foi de $31 \%$.

No Brasil, a Associação Brasileira Multiprofissional de Proteção à Infância e Adolescência (ABRAPIA) realizou uma pesquisa no Rio de Janeiro, entre 2002 e 2003. Participaram 5428 crianças, com idade média de 13,47 anos, sendo $50,5 \%$ meninos e $49,5 \%$ meninas. Destes, $16,9 \%$ identificaram-se como vítimas, 10,9\% vítimas / agressores, $12,7 \%$ agressores, e 57,5\% testemunhas (Lopes, 2005). Berger (2007) cita outros estudos de prevalência realizados por diversos autores em várias partes do mundo. Na Noruega foi encontrado um total de $12 \%$ de vítimas e $8 \%$ de agressores; em Portugal $20 \%$ de vítimas e $16 \%$ de agressores; em Malta $32 \%$ de vítimas e $27 \%$ de agressores e em escolas rurais dos Estados Unidos foi encontrado um total de $82 \%$ de vítimas.

\section{Os diferentes papéis no cenário do bullying}

No cenário do bullying os papéis se dividem, tradicionalmente, entre agressor, vítima, vítima/agressor e testemunhas. $O$ agressor do bullying é aquela criança que agride outra, supostamente mais fraca, com o objetivo de machucar, prejudicar ou humilhar, sem ter havido provocação por parte da vítima (Berger, 2007).

A vítima de bullying é aquela criança que é constantemente agredida pelos colegas e, geralmente, não consegue cessar ou reagir aos ataques (Lopes, 2005). Apresenta-se mais vulnerável à ação dos agressores por algumas características físicas, comportamentais ou emocionais. Podemos citar, dentre elas, o fato de ter poucos amigos, ser passivo, retraído e possuir baixa autoestima (Cantini, 2004). Vítima/ agressor é a denominação dada àquelas crianças que são tanto vítimas como agressores. Diferenciam-se dos agressores e vítimas típicos por serem impopulares e pelo alto índice de rejeição entre seus colegas (Lopes, 2005). Segundo Lopes (2005), estas crianças apresentam uma combinação de baixa autoestima, atitudes agressivas e provocativas e prováveis alterações psicológicas, merecendo atenção especial. Podem ser depressivas, ansiosas, inseguras e inoportunas, procurando humilhar os colegas para encobrir suas limitações. Apresentam dificuldades com o comportamento impulsivo, reatividade emocional e hiperatividade (Lopes, 2005).

As testemunhas são aquelas crianças e adolescentes que não se envolvem diretamente em bullying, mas participam como espectadores. Grande parte das testemunhas sente simpatia pelas vítimas e se sente mal ou triste ao pre- 
senciar colegas sendo vitimizados (Bandeira, 2009; Berger, 2007). A maioria das testemunhas não consegue apoiar ou auxiliar a vítima de bullying por não saber o que fazer, por ter medo de se tornar a próxima vítima ou por medo de fazer algo errado e causar ainda mais problemas (Berger, 2007).

\section{Diferenças de gênero}

Vários autores têm apontado diferenças entre meninas e meninos em relação ao bullying (Bandeira, 2009; Boulton \& Underwood, 1992; Gini \& Pozzoli, 2006; Lisboa, 2005; Sharp \& Smith, 1991). Comumente os meninos agridem tanto meninos quanto meninas, enquanto as meninas são agredidas principalmente por outras meninas (Boulton \& Underwood, 1992). A agressão física e a ameaça verbal são mais utilizadas pelos meninos, enquanto as meninas utilizam formas mais indiretas do bullying, como o uso de apelidos, fofocas e exclusão do grupo social (Sharp \& Smith, 1991). As meninas geralmente expressam atitudes mais positivas em relação às vítimas, são mais empáticas e dão mais suporte do que os meninos (Gini \& Pozzoli, 2006). Entre os meninos é mais comum a ocorrência de agressividade e vitimização (Liang, Flisher, \& Lombard, 2007). Os próprios meninos são classificados pelos seus colegas como agressores e como vítimas/agressores com uma frequência maior do que as meninas (Lisboa, 2005).

De acordo com Bandeira (2009), o bullying apresenta diferentes implicações na autoestima de meninas e meninos envolvidos nos diferentes papéis e variações de autoestima nos diferentes papéis para o mesmo sexo. Meninas que são vítimas/agressoras apresentam uma autoestima mais baixa do que meninos que são vítimas/agressores. Entre as meninas, baixos níveis de autoestima estão relacionados com o papel de vítima/agressor, o que não ocorre entre os meninos. O grupo de agressoras apresenta média mais alta de autoestima que o grupo de vítimas/agressoras. Em relação aos meninos, baixos níveis de autoestima estão relacionados ao papel de vítima. O grupo de testemunhas apresenta maior média de autoestima que o grupo das vítimas.

\section{O ambiente escolar e o comportamento agressivo}

A escola desempenha um papel de grande importância no desenvolvimento social de crianças e adolescentes. Constitui-se em um espaço de convivência e aprendizagem (Cantini, 2004), oportunizando a socialização de jovens na cultura ocidental moderna (Lisboa \& Koller, 2003). A escola proporciona a experiência de relações de hierarquia, vivências de igualdade e convívio com as diferenças, que, dentre outras, terão influência estruturante na formação do indivíduo (Cantini, 2004). Dessa forma, não pode ser considerada apenas como um espaço destinado à aprendizagem formal ou ao desenvolvimento cognitivo (Lisboa \& Koller, 2003). Conforme Lisboa (2005), as interações que ocorrem no contexto escolar são caracterizadas pela forte atividade social. É nesse ambiente que as crianças e os adolescentes têm a oportunidade de expandir sua rede de interações e relações para além da família, desenvolvendo autonomia, independência e aumentando sua percepção de pertencer ao contexto social. As habilidades sociais, juntamente com as características de personalidade, contribuem para determinar a forma com que o indivíduo se relaciona com seus pares e tal aprendizagem serve como um treinamento para o convívio em sociedade (Cantini, 2004).

O ambiente escolar serve como cenário de vários processos e fenômenos grupais, dentre eles a violência escolar. O termo violência escolar se refere a todos os comportamentos agressivos e antissociais, incluindo conflitos interpessoais, danos ao patrimônio e atos criminosos (Lopes, 2005). O comportamento agressivo no contexto escolar não é um problema recente, nem tão pouco um fenômeno novo. O comportamento agressivo surge na interação social e pode ser definido como todo o comportamento que visa causar danos ou prejuízos em alguém (Lisboa, 2005). Conforme Lisboa (2005), o comportamento agressivo pode ser considerado como um processo decorrente da interação que ocorre entre a pessoa e o seu ambiente físico, social e cultural através do tempo, uma vez que emerge na interação social. Dessa forma, a referida autora aponta que é possível afirmar que uma criança está agressiva e não que ela é agressiva.

Alguns comportamentos agressivos são esperados durante a adolescência e podem até mesmo ter benefícios adaptativos (Hawley, 1999). Entretanto, a agressão entre os pares não deve ser negligenciada ou tratada como parte do desenvolvimento. O bullying é um problema sério e pode trazer consequências graves aos envolvidos. Pesquisas têm associado a experiência de vitimização à baixa autoestima, sintomas físicos e emocionais, ansiedade, medo, cefaleia, enurese, evitação escolar, depressão, ideias suicidas e suicídio, entre outros (Bandeira, 2009; Berger, 2007; Cantini, 2004; Lopes, 2005; Olweus, 1993). Os efeitos do envolvimento em bullying podem persistir por toda a vida escolar e durante a vida adulta (Rigby, 1998; Olweus, 1993). A adolescência é identificada na literatura como sendo o período de maior ocorrência de bullying (Kenny, Mceachern, \& Aluede, 2005). Estudos apontam que o momento de maior incidência dos episódios de bullying e violência escolar ocorre entre os nove e os quinze anos de idade (Rolim, 2008).

\section{Método}

O presente estudo seguiu um delineamento do tipo correlacional de corte transversal. Participaram 465 alunos, crianças e adolescentes, de quartas a oitavas séries do ensino fundamental de três escolas (duas públicas e uma privada) da cidade de Porto Alegre, RS. A idade variou entre nove e 18 anos $(M=13,4 ; d p=1,47)$, sendo $52,7 \%$ do sexo masculino. A amostra foi de conveniência e a participação dos alunos foi voluntária. Este estudo foi aprovado pelo Comitê de Ética em Pesquisa do Instituto de Psicologia da Universidade Federal do Rio Grande do Sul. 


\section{Instrumentos}

Foi utilizado um questionário sobre bullying que contou com 15 questões de múltipla escolha em que os alunos puderam se identificar como participantes, ou não, de bullying. Algumas das questões possibilitaram a escolha de mais de uma opção, permitindo sobreposições de algumas categorias a priori. O questionário possibilitou identificar os tipos e formas de bullying e a frequência com que ocorrem. Possibilitou também a identificação das crianças e adolescentes enquanto vítimas, agressores, vítimas/agressores e testemunhas.

\section{Procedimentos}

Inicialmente, foi encaminhado um termo de consentimento livre e esclarecido para assinatura dos pais ou responsáveis de todos os participantes. O questionário foi aplicado coletivamente em sala de aula, em dias e horários designados previamente. A coleta dos dados teve a duração de 50 minutos. Antes de iniciar a aplicação do questionário, a pesquisadora realizou um rapport, no qual explicou aos alunos sobre os objetivos da pesquisa e o significado do termo bullying, citando alguns exemplos e sempre utilizando uma linguagem apropriada para a faixa etária dos participantes. Foi esclarecida a diferença entre bullying e agressões ocasionais e as características peculiares do bullying. Os alunos foram informados que sua participação era voluntária e que poderiam interrompê-la a qualquer momento, sem nenhuma penalidade. Também foram informados sobre o sigilo e a confidencialidade dos dados e de que não deviam se identi- ficar nos questionários. Os únicos dados pessoais coletados foram idade, sexo, com quem reside e o número de irmãos.

\section{Resultados}

Os dados foram analisados através do software aplicativo para análise estatística Statistical Package for the Social Sciences, SPSS 13.0. Foram feitas análises descritivas e testes Qui-quadrado.

A Tabela 1 mostra a distribuição das frequências entre as categorias de papéis de bullying por sexo. Foram encontradas diferenças significativas entre os sexos nos diferentes papéis de bullying mostrando que as meninas se identificaram mais como vítimas e testemunhas e os meninos, mais como agressores e vítima/agressores $\left(x^{2}=10,8\right.$, $d f=3, p<0,05)$.

Na Tabela 2 é possível verificar os tipos de bullying mais utilizados contra as vítimas. Foram encontradas diferenças significativas entre os sexos mostrando que os meninos utilizaram mais empurrões, chutes e socos $\left(X^{2}=5,1\right.$, $d f=1, p<0,05)$ e as meninas utilizaram mais mentiras e fofocas $\left(x^{2}=6,7, d f=1, p<0,05\right)$.

Quanto ao sexo do agressor, as vítimas relataram que $50,0 \%$ dos ataques foram realizados por meninos, $31,2 \%$ tanto por meninos quanto por meninas e 18,8\% dos ataques foram realizados por meninas. As meninas relataram que $20,9 \%$ dos ataques foram realizados por meninas e $2 \%$ por meninos. Os meninos relataram que $36,7 \%$ dos ataques foram realizados por meninos e $20,9 \%$ por meninas. Foram encontradas diferenças significativas entre os sexos mos-

Tabela 1. Frequência e percentual das categorias dos papéis de bullying por sexo.

\begin{tabular}{lcccc}
\hline Papéis & Categorias & Categ. puras & Meninas & \multicolumn{1}{l}{ Meninos } \\
\hline Vítima & $276(67,5 \%)$ & $98(23,2 \%)$ & $57(25,9 \%)$ & $41(16,7 \%)$ \\
Agressor & $252(54,7 \%)$ & $67(15,9 \%)$ & $23(10,5 \%)$ & $44(18,0 \%)$ \\
Vít./agressor & & $184(43,6 \%)$ & $80(36,4 \%)$ & $104(42,2 \%)$ \\
Testemunha & $390(83,9 \%)$ & $73(17,3 \%)$ & $38(17,3 \%)$ & $35(14,3 \%)$ \\
Não participa & $43(9,2 \%)$ & & & \\
\hline N & 465 & 422 & 198 & 224 \\
\hline
\end{tabular}

Tabela 2. Frequência e percentual do tipo de bullying mais utilizado segundo as vitimas por sexo.

\begin{tabular}{llll}
\hline Tipo de bullying & \multicolumn{1}{c}{ Total } & \multicolumn{1}{c}{ Meninas } & \multicolumn{1}{c}{ Meninos } \\
\hline Apelido, insulto, deboche & $171(61,1 \%)$ & $85(38,6 \%)$ & $86(35,1 \%)$ \\
Mentira, fofoca & $72(25,7 \%)$ & $45(20,5 \%)$ & $27(11 \%)$ \\
Ameaça & $54(19,35 \%)$ & $24(10,9 \%)$ & $30(12,2 \%)$ \\
Empurrão, chute, soco & $35(12,5 \%)$ & $11(5,0 \%)$ & $24(9,8 \%)$ \\
Isolamento & $19(6,8 \%)$ & $10(4,5 \%)$ & $9(3,7 \%)$ \\
Quebra ou roubo de material & $10(3,6 \%)$ & $4(1,8 \%)$ & $6(2,4 \%)$ \\
\hline $\mathrm{N}$ & 280 & 138 & 142 \\
\hline
\end{tabular}


trando que os meninos foram mais agredidos por meninos e as meninas foram mais agredidas por meninas $\left(X^{2}=47,2\right.$, $d f=2, p<0,05)$. Em relação à quantidade de agressores, as vítimas relataram que em $67,7 \%$ dos casos os ataques foram feitos por mais de dois colegas.

Quanto ao sentimento gerado nas vítimas, 48,9\% disseram ter ficado com raiva após os episódios de bullying e 31,8\% disseram que a situação não incomodou. Já 21,2\% ficaram preocupados com os outros, 10,8\% ficaram com medo e $9,4 \%$ não queriam mais ir à escola. Foram encontradas diferenças significativas entre os sexos mostrando que os meninos referiram que o fato de ser vítima de bullying não incomodou $\left(x^{2}=12,3, d f=2, p<0,05\right)$ e as meninas referiram que o fato de sofrer bullying fez com que elas não quisessem mais ir à escola $\left(x^{2}=4,9, d f=1, p<0,05\right)$.

A maioria das vítimas relatou que reagiu aos ataques se defendendo $(47,5 \%)$ ou ignorando o fato $(47,3 \%)$. Outros pediram ajuda de adultos $(13,3 \%)$, choraram $(10,4 \%)$ ou fugiram $(2,9 \%)$. Foram encontradas diferenças significativas entre os sexos mostrando que os meninos fugiram mais dos ataques $\left(X^{2}=4,4, d f=1, p<0,05\right)$.

Em relação à tentativa dos colegas em ajudar as vítimas durante os ataques, 33,8\% tentaram ajudar e a situação melhorou, 30,9\% não tentaram nada, 26,4\% tentaram ajudar e o bullying piorou e $9,7 \%$ não sabiam que os colegas estavam sofrendo bullying.
A Tabela 3 mostra os possíveis motivos que levam alguns colegas a fazer bullying contra outros. A categoria "outros motivos" incluiu preconceito, falta de respeito, inveja ou ciúmes dos agressores, porque os agressores são impunes ou porque eles "se acham". Foram encontradas diferenças significativas entre os sexos mostrando que os meninos acreditam que um dos motivos para o bullying ocorrer é por brincadeira $\left(x^{2}=4,3, d f=1, p<0,05\right)$ ou porque os agressores são mais fortes $\left(x^{2}=5,4, d f=1, p<0,05\right)$. As meninas acreditam que o bullying ocorre por outros motivos $\left(x^{2}=17,9, d f=1, p<0,05\right)$.

Um total de 390 alunos $(83,9 \%)$ disse ter sido testemunha de bullying. Desses, 37,8\% não fizeram nada, 31,6\% pediram para o agressor parar, $21,3 \%$ ajudaram a vítima e $15,7 \%$ pediram ajuda na escola. Foram encontradas diferenças significativas entre os sexos na opção "não fez nada" mostrando que os meninos testemunhas reagiram menos do que as meninas $\left(x^{2}=4,3, d f=1, p<0.05\right)$.

Quanto ao sentimento dos estudantes que foram testemunhas, a maioria $(78,6 \%)$ disse ter se sentido mal ou triste ao presenciar colegas sendo vitimizados, $20,7 \%$ ignoraram e 5,9\% ficaram com medo de acontecer o mesmo com ele. Foram encontradas diferenças significativas entre os sexos mostrando que as meninas se sentiram pior do que os meninos $\left(x^{2}=22,8, d f=1, p<0,01\right)$ e os meninos ignoraram mais o fato do que as meninas $\left(X^{2}=19,8, d f=1, p<0,01\right)$. Não houve diferença significativa na categoria medo.

Tabela 3. Frequência e percentual dos possíveis motivos para a prática do bullying por sexo.

\begin{tabular}{llll}
\hline Possíveis motivos & \multicolumn{1}{c}{ Total } & \multicolumn{1}{c}{ Meninas } & \multicolumn{1}{c}{ Meninos } \\
\hline Por brincadeira & $186(40,2 \%)$ & $77(35,0 \%)$ & $109(44,5 \%)$ \\
A vítima é diferente & $96(20,7 \%)$ & $49(22,3 \%)$ & $47(19,2 \%)$ \\
Não sabe a causa & $94(20,3 \%)$ & $49(22,3 \%)$ & $45(18,4 \%)$ \\
Os agressores são mais fortes & $94(20,3 \%)$ & $25(11,4 \%)$ & $47(19,2 \%)$ \\
Os agressores são provocados & $24(5,2 \%)$ & $13(5,9 \%)$ & $11(4,5 \%)$ \\
A vítima merece o castigo & $8(1,7 \%)$ & $4(1,8 \%)$ & $4(1,6 \%)$ \\
Outros motivos & $89(19,2 \%)$ & $60(27,3 \%)$ & $29(11,8 \%)$ \\
\hline $\mathrm{N}$ & 463 & 219 & 244 \\
\hline
\end{tabular}

Tabela 4. Frequência e percentual da quantidade de agressores por sexo.

\begin{tabular}{llll}
\hline Quantidade de agressores & \multicolumn{1}{c}{ Total } & \multicolumn{1}{c}{ Meninas } & Meninos \\
\hline Nunca fiz bullying & $209(45,3 \%)$ & $114(51,8 \%)$ & $95(38,8 \%)$ \\
Fiz sozinho & $64(13,9 \%)$ & $20(9,1 \%)$ & $44(18,0 \%)$ \\
Fiz com um ou mais colegas & $111(24,1 \%)$ & $53(24,1 \%)$ & $58(23,7 \%)$ \\
Fiz com três a seis colegas & $66(14,3 \%)$ & $28(12,7 \%)$ & $38(15,5 \%)$ \\
Fiz com mais de oito colegas & $11(2,4 \%)$ & $2(0,9 \%)$ & $9(3,7 \%)$ \\
\hline N & 461 & 217 & 244 \\
\hline
\end{tabular}


Tabela 5. Frequência e percentual do tipo de bullying segundo agressores por sexo.

\begin{tabular}{lcll}
\hline Tipo de bullying & \multicolumn{1}{c}{ Total } & Meninas & \multicolumn{1}{c}{ Meninos } \\
\hline Apelido, insulto, deboche & $183(70,7 \%)$ & $75(34,1 \%)$ & $108(44,1 \%)$ \\
Empurrão, chute, soco & $40(15,4 \%)$ & $11(5,0 \%)$ & $29(11,8 \%)$ \\
Ameaça & $35(13,5 \%)$ & $16(7,3 \%)$ & $19(7,8 \%)$ \\
Isolamento & $18(6,9 \%)$ & $7(3,2 \%)$ & $11(4,5 \%)$ \\
Mentira, fofoca & $17(6,6 \%)$ & $10(4,5 \%)$ & $7(2,9 \%)$ \\
Quebra ou roubo de material & $5(1,9 \%)$ & 0 & $5(2,0 \%)$ \\
\hline $\mathrm{N}$ & 259 & 107 & 152 \\
\hline
\end{tabular}

Tabela 6. Frequência e percentual do sentimento dos agressores por sexo.

\begin{tabular}{lccc}
\hline Sentimento dos agressores & Total & Meninas & Meninos \\
\hline Achou engraçado & $94(35,9 \%)$ & $36(16,4 \%)$ & $58(23,7 \%)$ \\
Sentiu mal & $64(24,4 \%)$ & $29(13,2 \%)$ & $35(14,3 \%)$ \\
Fariam o mesmo comigo & $49(18,7 \%)$ & $23(10,5 \%)$ & $26(10,6 \%)$ \\
Sentiu nada & $35(13,4 \%)$ & $16(7,3 \%)$ & $19(7,8 \%)$ \\
Eles mereciam & $33(12,6 \%)$ & $14(6,4 \%)$ & $19(7,8 \%)$ \\
Sentiu bem & $16(6,1 \%)$ & $1(0,5 \%)$ & $15(6,1 \%)$ \\
Medo ser descoberto & $9(3,4 \%)$ & $6(2,7 \%)$ & $3(1,2 \%)$ \\
\hline $\mathrm{N}$ & 262 & 107 & 155 \\
\hline
\end{tabular}

Da amostra estudada, $54,7 \%$ dos alunos se identificaram com agressores. Destes, a maioria (40,8\%) o fez com um ou mais colegas. A Tabela 4 apresenta a quantidade de colegas que participaram dos ataques, segundo os agressores. Foram encontradas diferenças significativas entre os sexos mostrando que os meninos se identificaram mais como agressores do que as meninas $\left(x^{2}=15,4, d f=4\right.$, $p<0,05)$.

Quando questionados sobre quantas vezes ajudaram a fazer bullying contra outros colegas, 49,1\% responderam afirmativamente à questão. Foram encontradas diferenças significativas entre os sexos mostrando que os meninos $(55,2 \%)$ afirmaram que ajudaram colegas a fazer bullying com mais frequência do que as meninas $(42,4 \%)\left(x^{2}=10,6\right.$, $d f=4, p<0,05)$. Segundo relato dos agressores, o tipo de bullying mais utilizado por eles foi o tipo verbal, com a utilização de apelido, insulto ou deboche $(70,7 \%)$, seguido do tipo físico com a utilização de empurrão, chute ou soco $(15,4 \%)$, conforme mostra a Tabela 5. Foram encontradas diferenças marginalmente significativas entre os sexos mostrando que os meninos utilizaram mais empurrões, chutes e socos $\left(x^{2}=3,7, d f=1, p<0,055\right)$, enquanto as meninas utilizaram mais a mentira e a fofoca $\left(x^{2}=3,6, d f=1, p<0,06\right)$. O relato dos agressores é confirmado pelas vítimas, o que pode ser verificado comparando as Tabelas 2 e 5.

A Tabela 6 mostra os sentimentos dos agressores em relação aos episódios de bullying. Foram encontradas diferenças significativas entre os sexos apenas na categoria "sentiu bem", mostrando que os meninos se sentiram bem ao fazer bullying contra colegas $\left(x^{2}=8,4, d f=1, p<0,05\right)$. 


\section{Discussão}

Os achados deste estudo apontaram para um número alto de alunos que se identificaram como participantes de bullying. Do total da amostra estudada, 67,5\% afirmaram ter sido vítima de bullying na escola. Os resultados mostraram que meninos e meninas experienciam níveis similares de vitimização. Esses dados contrariam os achados de Liang e cols. (2007) que afirmam que a agressividade e a vitimização são de ocorrência mais comum entre os meninos. Quanto aos alunos agressores, 54,7\% dos participantes se identificaram como tal. Os meninos relataram que foram mais agredidos por meninos e as meninas, mais agredidas por meninas. Esses dados corroboram a literatura (Boulton \& Underwood, 1992), que afirma que comumente os meninos agridem tanto meninos quanto meninas, enquanto as meninas são agredidas principalmente por outras meninas. Em relação às testemunhas, $83,9 \%$ dos adolescentes testemunharam colegas sendo vitimizados por outros colegas. Dentre os 465 participantes, apenas 43 (9,2\%) referiram não ter se envolvido em bullying de forma alguma. Esses dados representam um número bem elevado de alunos que se identificaram como vítimas, agressores e testemunhas de bullying e diferem de dados encontrados em outros estudos. Estudos nacionais apontam para uma percentagem mais baixa de alunos envolvidos em bullying, como é possível verificar no estudo realizado pela ABRAPIA no Rio de Janeiro (Lopes, 2005), que identificou um total de 16,9\% de vítimas, $12,7 \%$ de agressores e $57,5 \%$ de testemunhas. Já os estudos estrangeiros divergem bastante em seus achados, com $12 \%$ de vítimas na Noruega, $20 \%$ de vítimas e $16 \%$ de agressores em Portugal, $32 \%$ de vítimas e $27 \%$ agressores em Malta e $82 \%$ de alunos vitimizados em escolas rurais dos Estados Unidos (Berger, 2007).

O número alto de alunos que se identificou como sendo tanto agressor quanto vítima foi superior ao esperado inicialmente. Esses dados podem ser explicados pela literatura (Berger, 2007), que aponta para grandes variações em frequência e tipo de bullying entre as nações, entre as regiões de uma mesma nação e entre as escolas de uma mesma região. Sendo o bullying um fenômeno multicausal, são muitos os fatores envolvidos que podem contribuir para essas diferenças. Podemos citar como exemplo a metodologia empregada na coleta de dados, as diferenças entre as escolas estudadas, as diferenças que ocorrem entre as nações, a cultura de cada local, a classe social, a etnia, a idade e o sexo dos participantes (Berger, 2007). É possível que o procedimento realizado no presente estudo tenha sido um fator de influência nas respostas dos participantes. Os achados deste estudo corroboram os dados encontrados pela United Nation (U. N.) (Berger, 2007), que apresentaram alta prevalência de alunos envolvidos em bullying. $O$ procedimento realizado na presente pesquisa se assemeIhou ao realizado pela U.N., que definiu o termo bullying na linguagem local antes da aplicação das questões, permitindo que todas as crianças pudessem interpretar bullying da mesma forma. No presente estudo foi realizado um rapport antes da aplicação do instrumento, no qual a pesquisadora explicou aos alunos sobre o significado do termo bullying e citou alguns exemplos, com a utilização de uma linguagem apropriada para a faixa etária dos participantes. Esse procedimento objetivou certificar que todos os participantes tinham conhecimento do significado do termo bullying, por se tratar de um termo estrangeiro que possui um sentido específico e rico em determinações.

Quanto às diferenças encontradas entre o presente estudo e os achados da ABRAPIA, é possível que os cinco anos que distanciam estes dois estudos exerçam alguma influência nos resultados obtidos. O termo bullying tornou-se mais conhecido no Brasil durante esse período. Entre os adolescentes, o surgimento do jogo eletrônico denominado Bully, em 2006, proporcionou um conhecimento maior do termo e de suas ações. Bully (Rockstar Games) é um jogo eletrônico que aborda a prática do bullying, tendo como cenário uma escola fictícia onde os estudantes praticam ataques a colegas e professores. Outro fator que possivelmente influenciou na diferença encontrada entre as duas pesquisas foi a metodologia utilizada, uma vez que a ABRAPIA não realizou rapport inicial, nem explicou aos alunos o significado do termo bullying antes da coleta dos dados.

No que se refere ao tipo de bullying mais utilizado, tanto as vítimas quanto os agressores afirmaram que foi o tipo verbal. Esses dados corroboram a literatura (Berger, 2007), que aponta para o tipo verbal como sendo o tipo de bullying mais utilizado durante a adolescência, tanto por meninos quanto por meninas. Esse tipo de bullying pode passar, muitas vezes, despercebido pelos adultos que convivem com as crianças e os adolescentes, tanto na escola quanto na família. Pais e professores apresentam maior tendência para cessar o bullying físico do que o bullying verbal. Muitos adultos acreditam que a agressão verbal não é tão prejudicial como os ataques físicos. Por não ser tão visível como a agressão física, que pode deixar marcas evidentes, as marcas deixadas pelo bullying verbal são, de certa forma, silenciosas, porém graves. Quanto às diferenças entre os sexos, os achados desta pesquisa indicaram que os meninos utilizaram mais empurrões, chutes e socos e as meninas utilizaram mais mentiras e fofocas. Esses dados corroboram a literatura (Sharp \& Smith, 1991), que aponta que os meninos tendem a utilizar a agressão física e a ameaça verbal, enquanto as meninas utilizam formas mais indiretas de bullying, como agressão verbal, apelido, insulto e fofoca.

A maioria das vítimas disse ter sido agredida por dois ou três colegas. Quanto aos agressores, a maioria relatou ter feito bullying juntamente com mais de um colega, ou mesmo ajudado alguns colegas a fazer bullying contra outros. Os resultados deste estudo demonstraram que isso ocorre com maior frequência entre os meninos. Esses achados reforçam a literatura (Berger, 2007; Cantini, 2004; Lopes, 2005; Olweus, 1993; Rigby, 1998), que aponta para a assimetria de forças presente na dinâmica do bullying. Tal assimetria pode ocorrer pela diferença numérica, em que vários estudantes agem de forma agressiva contra uma única vítima, ou pela diferença de força ou poder que estão presentes 
nas situações de bullying. A humilhação está presente nas situações onde o agressor submete as vítimas a situações vexatórias com o intuito de que elas se sintam inferiorizadas.

Quanto ao sexo do agressor, as vítimas relataram que a maioria dos ataques foi realizada por meninos. Os próprios meninos se identificaram mais como agressores do que as meninas. Esses achados corroboram a literatura (Berger, 2007; Lopes, 2005; Olweus, 1993), que aponta para o predomínio do sexo masculino entre os agressores. Esse fato, entretanto, não pode ser indicativo de que os meninos sejam mais agressivos do que as meninas, mas apenas que eles apresentam maior probabilidade de envolvimento em bullying. Mais estudos são necessários para determinar as diferenças de gênero no envolvimento de meninos e meninas em situações de bullying.

Em relação ao sentimento causado pelo bullying, a maioria das vítimas $(48,9 \%)$ disse ter ficado com raiva. Quanto às diferenças entre os sexos, os meninos referiram que ser vítima de bullying não incomodou. Já para as meninas, o fato de sofrer bullying fez com que elas não quisessem mais ir à escola. A maioria dos agressores (35,9\%) achou engraçado o fato de agredir outros colegas, e os meninos relataram que se sentiram bem ao fazer bullying. Esses dados encontram apoio na literatura (Lopes, 2005), que afirma que os agressores veem sua agressividade como qualidade e têm opiniões positivas sobre si mesmo. Sentem prazer e satisfação em dominar, controlar e causar dano aos outros.

Ao sofrer bullying, a maioria das vítimas afirmou ter se defendido dos ataques ou ignorado o fato. Os meninos referiram com maior frequência do que as meninas que reagiram ao bullying fugindo dos ataques. É possível que as vítimas que se defenderam pertençam ao grupo vítima/ agressor, uma vez que a literatura (Lopes, 2005) aponta que a vítima típica, em geral, não dispõe de recursos, status ou habilidade para reagir ou cessar o bullying. A maioria dos adolescentes $(60 \%)$ tentou ajudar os colegas que estavam sendo vitimizados. O percentual de vítimas que pediu ajuda de um adulto foi baixo, ficando em 13,3\%. É possível que o medo ou a vergonha impeçam as vítimas de buscar mais ajuda junto aos adultos, tornando-as mais vulneráveis à ação dos agressores.

Em relação aos possíveis motivos para a prática do bullying, a maioria dos estudantes $(40,2 \%)$ acredita que o motivo pelo qual alguns colegas fazem bullying contra outros é por brincadeira. Em relação às diferenças entre os sexos, os meninos acreditam que um dos motivos para o bullying é a brincadeira ou porque os agressores são mais fortes. Já as meninas acreditam que a causa para o bullying são outros motivos. Esses achados contrariam os resultados de um estudo feito por Almeida, Lisboa e Caurcel (2007), que investigou as possíveis causas dos maus tratos entre os pares. Os autores encontraram como possível motivo para o bullying os estereótipos (28,4\%), seguido da comparação social. É plausível que essas diferenças tenham ocorrido por diferenças metodológicas. O presente estudo utilizou um questionário com questões de múltipla escolha, enquanto o estudo realizado por Almeida e cols. (2007) utilizou questões abertas. Esses dados apontam para a importância da conscientização por parte de alunos, pais, escola e comunidade de que o bullying é um problema sério e, como tal, não deve ser tolerado. O fato de muitos alunos perceberem o bullying como uma brincadeira alerta para a naturalização de um fenômeno grave e frequente no cenário escolar. Alerta também para a preponderância de um modelo individualista e a falta de sentimento de coletividade presente nos relacionamentos.

A maioria das testemunhas não fez nada quando presenciou os colegas sendo vitimizados. Os resultados mostraram que os meninos testemunhas reagiram menos e ignoraram mais o fato do que as meninas. Estas, por sua vez, se sentiram pior do que os meninos. Esses dados corroboram a literatura (Berger, 2007), que afirma que a maior parte das testemunhas não se envolve diretamente em atos de bullying e geralmente se cala por medo de ser a próxima vítima, por não saber como agir e por não acreditar nas atitudes da escola. Em relação ao sentimento gerado nos estudantes que foram testemunhas, a grande maioria $(78,6 \%)$ relatou que se sentiu mal, triste ou com pena da vítima. Esses dados são comprovados pela literatura (Lopes, 2005; Rolim, 2008), que afirma que grande parte das testemunhas sente simpatia pelos alvos, tende a não culpá-los pelo ocorrido, condena o comportamento dos agressores e deseja que os professores intervenham efetivamente.

\section{Considerações finais}

Os resultados encontrados neste estudo apontaram para diferenças entre meninos e meninas quanto ao fenômeno bullying. Foram encontradas diferenças no tipo de bullying utilizado, no sentimento e reação das vítimas e testemunhas, no sentimento dos agressores, no sexo dos agressores e nos possíveis motivos para a prática do bullying. Meninos e meninas expressam sua agressividade de diferentes formas. Meninas podem ser tão agressivas quanto meninos, entretanto a expressão da agressividade apresenta variações nos gêneros. As diferenças de comportamento entre meninos e meninas são fortemente influenciadas pelas expectativas culturais de cada gênero (Gini \& Pozzoli, 2006). Os sexos são tratados de forma distinta em resposta às expectativas geradas sobre seus comportamentos, valorizando comportamentos agressivos nos diferentes sexos. A expressão da agressividade pode variar pelas diferentes expectativas culturais dos papéis de gênero. Os papéis de cada gênero decorrem da transmissão social advinda dos múltiplos sistemas presentes na vida cotidiana, como a família e a escola. As diferentes expectativas em relação aos gêneros contribuem para que o bullying seja analisado de forma diferenciada entre meninos e meninas.

Os resultados apontaram para um número elevado de crianças e adolescentes envolvidos em bullying. Foi possível verificar que esse é um fenômeno de ocorrência muito comum no cenário escolar, com grande percentagem de alunos envolvidos nos diferentes papéis. Representa um fenômeno universal observável em praticamente todas as 
escolas. Mesmo fazendo parte da vida escolar de crianças e adolescentes há muito tempo, os estudos relacionados ao tema têm apontado para a gravidade das consequências entre os estudantes envolvidos. Os achados sugerem a necessidade de novas pesquisas que avaliem mais amplamente as diferenças de gênero envolvidas no bullying. Tal avaliação irá permitir melhores intervenções para o fenômeno e uma melhor compreensão da complexa interação entre os diferentes fatores individuais e do contexto, presentes no fenômeno do bullying. As estratégias antibullying exigem um comprometimento das escolas com o desenvolvimento de trabalhos contínuos de prevenção, adotando condutas adequadas que possam reduzir esse problema de forma eficaz.

As ações de prevenção contra o bullying devem incluir em primeiro lugar o conhecimento, por parte de toda a comunidade escolar, acerca do fenômeno. Devem ser instituídas políticas públicas que priorizem a redução e prevenção do bullying nas escolas de todo o país. É necessário investimento e treinamento de profissionais da área da educação para elaboração e execução de programas de prevenção ao bullying. Torna-se necessária a tomada de consciência das graves consequências desse fenômeno que merece a atenção de pesquisadores, professores e profissionais que atuam nas escolas, pais e comunidade em geral.

\section{Referências}

Almeida, A., Lisboa, C., \& Caurcel, M. J. (2007). ¿Porqué ocurren los malos tratos entre iguales? Explicaciones causales de adolescentes portugueses y brasileños. Revista Interamericana de Psicologia, 41(2), 107-118.

Bandeira, C. M. (2009). Bullying: autoestima e diferenças de gênero. Dissertação de Mestrado, Instituto de Psicologia, Universidade Federal do Rio Grande do Sul, Porto Alegre.

Berger, K. S. (2007). Update on bullying at school: Science forgoten? Developmental Review, 27, 90-126.

Boulton, M. J., \& Underwood, K. (1992). Bully/victim problems among middle school children. British Journal Educational Psychology, 62, 73-87.

Cantini, N. (2004). Problematizando o bullying para a realidade brasileira. Dissertação de Mestrado, Programa de Pós-Graduação em Psicologia do Centro de Ciências da Vida, Pontifícia Universidade Católica de Campinas, Campinas, São Paulo.
Gini, G., \& Pozzoli, T. (2006). The role of masculinity in children's bullying. Sex Roles, 54, 585-588.

Hawley, P. H. (1999). The ontogenesis of social dominance: A strategy-based evolutionary perspective. Developmental Review, 19, 97-132.

Kenny, M. C., Mceachern, A. G., \& Aluede, O. (2005). Female bullying: Prevention and counseling interventions. Journal of Social Sciences, 8, 13-19.

Liang, H., Flisher, A. J., \& Lombard, C. J. (2007). Bullying, violence and risk behavior in South African school students. Child Abuse \& Neglect, 31, 161-171.

Lisboa, C. S. M. (2005). Comportamento agressivo, vitimização e relações de amizade em crianças em idade escolar: fatores de risco e proteção. Tese de Doutorado, Programa de Pós-Graduação em Psicologia do Desenvolvimento, Instituto de Psicologia, Universidade Federal do Rio Grande do Sul, Porto Alegre..

Lisboa, C., \& Koller, S. H. (2003). Interações na escola e processos de aprendizagem: fatores de risco e proteção. Em E. Boruchovitch \& J. A. Bzuneck (Eds.), Aprendizagem: processos psicológicos e o contexto social na escola (pp. 201-224). Petrópolis, RJ: Vozes.

Lopes, A. A. N. (2005). Programa de reducción del comportamiento agresivo entre estudiantes. Em C. B. Silva \& C. M. Lisboa (Eds.), Violencia escolar (pp. 297-335). Santiago de Chile: Universitária.

Olweus, D. (1993). Bullying at school. What we know and what we can do. Oxford, UK: Blackwell.

Rigby, K. (1998). The relationship between reported health and involvement in bully/victim problems among male and female secondary school students. Journal of Health Psychology, 3(4), 465-476.

Rolim, M. (2008). Bullying: o pesadelo da escola, um estudo de caso e notas sobre o que fazer. Dissertação de Mestrado, Programa de Pós-Graduação em Sociologia, Instituto de Sociologia, Universidade Federal do Rio Grande do Sul, Porto Alegre.

Sharp, S., \& Smith, P. K. (1991). Bullying in UK schools: The DES Sheffield Bullying Project. Early Childhood Development and Care, 77, 47-55. 


\section{Sobre os autores}

Cláudia de Moraes Bandeira (kkbandeira @hotmail.com)

Psicóloga formada pela Pontifícia Universidade Católica do Rio Grande do Sul (PUC-RS), Mestre e Doutoranda em Psicologia pela Universidade Federal do Rio Grande do Sul (UFRGS). Endereço: Rua Ramiro Barcelos, 2600-Térreo. Bairro Santa Cecília - CEP: 90035-003

Claudio Simon Hutz (claudio.hutz@terra.com.br)

PhD na University of lowa, professor titular do Instituto de Psicologia da Universidade Federal do Rio Grande do Sul (UFRGS).

Trabalho derivado da dissertação de mestrado intitulada Bullying: autoestima e diferenças de gênero, da aluna Cláudia de Moraes Bandeira. 